\title{
ESTRATÉGIA DA ÁFRICA DO SUL PÓS-APARTHEID COMO LÍDER REGIONAL DA SADC
}

\author{
POST-APARTHEID SOUTH AFRICA STRATEGY AS REGIONAL LEADER OF SADC
}

Luiz Henrique Apollo ${ }^{1}$

\section{RESUMO}

O artigo examina o envolvimento da África do Sul pós-apartheid para se tornar o líder regional da África Austral como parte da projeção geoestratégica do país internacionalmente. Apesar das dificuldades de superar as instabilidades socioeconômicas e políticas da região, o país tenta estabelecer o seu envolvimento através de cooperação Sul-Sul com o fim de se consolidar como o catalizador, facilitador e gerenciador do bloco econômico da SADC.

Palavras-chave: África do Sul; Cooperação Sul-Sul; SADC.

\section{ABSTRACT}

The paper analyses the involvement of post-apartheid South Africa to become the regional leader in the southern Africa as part of the geo-strategic projection of the country internationally. Despite the difficulties of overcoming the socio-economic and political instability in the region, the country attempts to establish their involvement through South-South cooperation in order to consolidate itself as the catalyst, facilitator and manager of the economic bloc of SADC.

Keywords: South Africa; South-South Cooperation; SADC.

\section{Introdução}

Diante de um contexto no século XXI de multipolarização e estruturação em blocos regionais onde novos atores internacionais começam a entrar em discussão, a cooperação Sul-Sul e novas parcerias estratégicas começam a entrar em voga. Apesar de pouca relevância, o crescimento do PIB com média de 4,9\% de 2006 a 2013, com população de 1,13 bi de aumento médio de 2,5\% ao ano (African Economic Outlook,

\footnotetext{
${ }^{1}$ Pós-Graduado em Estudos Estratégicos Internacionais pela Faculdade de Ciências Econômicas da UFRGS. Artigo como quesito parcial para a obtenção do título de Pós-Graduado em Estudos Estratégicos Internacionais, sob a orientação do Prof. Dr. Paulo Vizentini, em julho de 2015. E-mail: luizhapollo@gmail.com. Porto Alegre, Brasil.

Conjuntura Global, vol. 4 n.3, set./dez., 2015, p. 478-494. 
2015) e um território de 38 milhões de $\mathrm{km}^{2}$, demonstra que o continente africano possui variedades de análises de Relações Internacionais que podem ser implantadas nesse espaço recentemente emancipado. Assim o sistema internacional também está se consolidando cada vez mais em regiões que se estruturam politicamente e economicamente a partir de suas peculiaridades.

O Southern African Development Community (SADC) é um exemplo de estrutura que visa um mercado comum econômico, político e cujos países inclusos possuem diferentes objetivos estratégicos. Dentro desse bloco, a África do Sul tenta estabelecer a sua liderança pela sua maior relevância econômica, de capital político, comercial e engajamento como mediador de conflitos na região, apesar das dificuldades em estabelecer coesão no grupo pela desconfiança de seus vizinhos, emanada pelo período do apartheid. Para um Estado emergente estabelecer liderança regional, conhecido como political entrepeneur, é necessária a construção de um espaço de valores comuns, compartilhamento de ações em defesa, infraestrutura, negócios, comércio e segurança humana e uma política externa que pressupõe cooperação (OLIVEIRA e ONUKI, 2006).

0 artigo é um fragmento de uma pesquisa maior, parte integrante para a obtenção do título de Pós-Graduado em Estudos Estratégicos Internacionais pela Universidade Federal do Rio Grande do Sul. Ele tem como objetivo geral demonstrar como se estabelece o envolvimento da África do Sul pós-apartheid na região da SADC considerada área estratégica para a projeção do país internacionalmente. De maneira específica, o artigo busca um marco histórico de comportamento da política externa dos últimos governos sul-africanos à região, mostrando quais foram as suas habilidades e vontades. Além do mais, o trabalho visa mostrar a importância da SADC, como ela se constitui e quais são os objetivos comuns de seus países, bem como avalia a relevância da África do Sul na região.

A metodologia trabalhada no artigo foi de uma pesquisa exploratória, baseada em autores como Landsberg, Yanacopolus, Kornegay, Habib, Otavio, Tscheola, Visentini, Pereira, Hamill e Lee, Prys, Krapohl, Simon, Soko, Hurrel, Bohler-Muller; de livros como Politics in Southern Africa: State \& Society in Transition, A África do Sul e o IBAS; revistas acadêmicas do Jornal of Contemporary of African Studies, South African Journal of International Affairs, Institute for Security Studies Pretoria, Africa Research Bulletin e 
dados estatísticos gerais do IPEA, UN Comtrade, dentre outros. Para tanto, é contextualizada historicamente a nova inserção da política externa sul-africana pósapartheid à região da África Austral, analisando principalmente as parcerias, discursos e ações estratégicas.

O artigo está em consonância com as teorias de relações internacionais que estabelecem o conceito de liderança regional de um país emergente, a determinação de sua política externa, bem como seu poder explanado multilateralmente rompendo com a dependência centro-periferia. A pesquisa enfoca no período pós-apartheid de Mandela, Mbeki e dá maior atenção a administração atual de Jacob Zuma como chefe de Estado explanando a sua condução para a consolidação de uma união entre os países da SADC.

Assim, na primeira parte o artigo avalia a política externa dos governos de Mandela, Mbeki e Zuma, principalmente com relação às parcerias estratégicas africanas. Depois, é demonstrado as características e objetivos comuns da região da África Austral e de seu principal bloco econômico, a SADC. Por fim, é explicada a importância geoestratégica do bloco e as tomadas de decisões de cooperação Sul-Sul e soft power que tem por fim o de projetar a região internacionalmente, de maneira próspera e segura, tendo como principal articulador a África do Sul.

\section{Política Externa Sul-Africana Pós-Apartheid}

O colonialismo e o regime do apartheid passado pela África do Sul deixaram muitas dificuldades sociais no país, sobretudo, para a maioria da população negra. Apesar de ter um PIB per capita e uma renda média alta, com crescimento ao redor de 3,5\% até a crise de 2008 (IMF World Economic Outlook, 2009), diversos desafios relacionados à desigualdade, alto desemprego, pobreza, violência e HIV-AIDS ainda devem ser superados. Após o embargo internacional, não houve resistência do Partido Nacional ao poder, o que gerou acordos e negociações internas com o Congresso Nacional Africano (CNA) que estava ascendendo ao poder. A estratégia que se desenvolveu foi de política econômica que garantisse a posição de prosperidade da elite 
branca, a reintegração dos territórios dos bantustões ${ }^{2}$ e a redivisão das províncias sulafricanas, além de um processo de paz, união com os países vizinhos e aumento dos direitos dos negros (VIZENTINI e PEREIRA, 2010).

Para estabelecer esse posicionamento, a política externa sul-africana pósapartheid modificou-se agindo em interação com as mudanças do contexto externo e doméstico, essencialmente pelo poder do CNA como articulador das medidas para reestruturar o país. Entretanto, a elite branca ainda persiste com seus privilégios econômicos e políticos, já que detém o poder de estruturar uma política liberal defendida pela federação empresarial e os organismos financeiros internacionais, deixando o governo com pouca articulação político-econômica. Assim, apesar dos direitos conquistados pelos negros ao voto, a livre circulação para a melhoria de vida e a busca de emprego, pouco se promoveu para diminuir as mazelas da desigualdade racial no país, deixando mais evidente a pobreza ocultada pelo antigo regime através da formação de favelas nas principais cidades da África do Sul (VIZENTINI, 2012).

Em 1994 quando o CNA ganha as eleições no país, Mandela (1994-1998) assume a presidência com grandes expectativas, principalmente por parte dos países ocidentais de uma "nova" África do Sul, que representaria a luta contra a pobreza, busca de pacificação do continente e realização do desenvolvimento através do auxílio da internacionalização da região. A sua política externa encontrava-se ideologicamente na adoção de medidas democráticas, ao mesmo tempo em que apoiava e se solidarizava politicamente aos regimes anti-apartheid da região ou que se fundamentassem na soberania nacional perante as intervenções externas (YANACOPULOS, 2012). Mandela considerava os direitos humanos fundamentais para as relações internacionais como problemas que vão além da política, além disso, a transformação mundial de crescente interdependência gerava necessidade de desenvolvimento da África junto de cooperação e combate à pobreza excessiva (OTAVIO, 2013).

\footnotetext{
${ }^{2}$ Os Bantustões foram pseudo-Estados de base tribal criados pelo regime do Apartheid para manter os negros fora dos bairros e terras brancas, mas sistematicamente perto delas para servirem de mão-de-obra barata. Através da Lei de Promoção do Autogoverno Banto, estabelecia-se um autogoverno (autonomia administrativa), sob a égide de Pretória, portanto, sem a possibilidade de autonomia política, o que consolidava e perpetuava o domínio por parte da minoria branca (PEREIRA, 2010).
} 
As diferenças que se mantinham nas tomadas de decisão no país tinham como consequência a desordem na maneira com que se conduzia a imagem da África do Sul internacionalmente e qual era o papel que ela exerceria: ora na adoção de uma postura complacente as ideias globais ocidentais ora uma perspectiva "Sulista", que persistia na importância do desenvolvimento local através da soberania e autoridade dos Estados da região Sul do mundo (HAMILL e LEE, 2001). 0 comportamento que elevou o país a sair do isolacionismo do regime do apartheid e a estabelecer uma democracia multirracial que buscava a resolução de conflitos de forma não violenta, a partir de sua posição de país intermediário e que almeja a liderança regional (HAMILL e LEE, 2001). Assim, a África do Sul usou de sua política de 'boa vizinhança' para ser o catalisador de iniciativas políticas para a região, dentro de uma postura cautelosa nas negociações com seus vizinhos, sempre sensível a possíveis acusações de dominação ou hegemonia, tenta portar-se como um facilitador para construir coalizões internacionais e gerenciador de instituições com a convenção de regras a níveis sub-regionais ou regionais (KORNEGAY, 2010).

A continuidade da missão de Mandela em relação à transformação do continente africano a partir da democracia, direitos humanos, negociador da paz, multilateralismo e universalismo foi seguido pelo seu sucessor à presidência da África do Sul Thabo Mbeki (1999-2008), que tinha como compromisso e convicção posicionar o país como um importante player global. Entretanto, diferentemente da primeira administração pósapartheid, a era Mbeki foi marcada por relativo sucesso no continente africano visto que a presença do país ficou mais intensificada. Mbeki estabelece, nas palavras de Landsberg (2000), "parcerias fundamentais", com Mugabe e Kagame, líderes do Zimbábue e Ruanda respectivamente, com quem necessita estar ao lado a fim de realizar o processo de estabilidade na região (OTAVIO, 2013). Com maior facilidade, iniciativas de negociação da África do Sul como mediador de conflitos foram tomadas entre 1994 e 2008 em Angola, Burundi, Lesoto, Quênia, Moçambique, Serra Leoa, Sudão e Zimbábue, além de missões de paz no Burundi, RDC, Comores, Eritreia-Etiópia, República Centro-Africana e Sudão (HABIB, 2009).

A estratégia tomada foi a demonstração de uma política externa para a chamada African Renassaince, o qual levava o papel de liderança sul-africana a partir do elevado investimento no desenvolvimento econômico, doações principalmente através de Conjuntura Global, vol. 4 n.3, set./dez., 2015, p. 478-494. 
organismos multilaterais como a FAO e impulso militar e diplomático de estabilização do continente. Através do programa político de princípios neoliberais "Crescimento, Emprego e Estratégia Distributiva" (GEAR, na sigla em inglês), os investimentos externos diretos do país aumentaram para \$31 bilhões em 2005 no continente africano comparado aos $\$ 2$ a \$3 bilhões por ano quinze anos antes em setores variados. Além do mais, os próprios indicadores de crescimento econômico demonstram que o PIB veio a uma taxa de $5 \%$ de aumento entre 2004 e 2006. Mesmo assim, esse desenvolvimento econômico estava atrelado à contenção de gastos do governo, baixos déficits fiscais, baixa inflação, privatização, desregulamentação, mínima intervenção estatal, o que mantinha os problemas sociais (HABIB, 2009).

Essa mesma lógica foi endereçada no estabelecimento do NEPAD (Nova Parceria Desenvolvimento África) na União Africana com o intuito de auxiliar o crescimento socioeconômico dos países africanos através do estabelecimento de um ambiente democrático, estável, sem corrupção. Entretanto, seu objetivo prático não lhes dá autonomia para o seu próprio desenvolvimento, já que sua integração visa gerar um ambiente próspero de negócios a um sistema de inserção globalizante de dependência (TSCHEOLA, 2002). Nesse contexto, a África do Sul na era Mbeki foi vista como a mediadora que assumia a liderança do NEPAD com valores ocidentais de 'boa governança', judiciário independente e de reformas econômicas liberalizantes em uma ponte entre o Norte e o Sul.

As críticas ao governo Mbeki principalmente dos grupos internos do CNA contrários as medidas neoliberais - no caso, o Congress of South African Trade Union (COSATU), o South African Communist Party (SACP) e a ANC Youth League (ANCYL) levaram a renúncia do presidente e elevaram o zulu Jacob Zuma a liderança do governo (LANDSBERG, 2012). Esperava-se de seu governo melhores garantias, acesso aos serviços públicos, dentro de uma reformulação do pensamento ideológico liberal através do aumento de investimento público em infraestrutura levado a cabo pelo Estado (HURREL, 2009) e uma política externa fundamentada em relações e cooperação de 
forma mais transparente, visando a liderança por atitudes não-hegemônicas que busca o próprio interesse através de soft power ${ }^{3}$ (LANDSBERG, 2012).

A continuidade de prioridade ao continente africano foi um ponto que Zuma permaneceu em sua política externa concernente a Mbeki, ampliando para além de assistências financeiras de forma multilateral e não-hegemônico. "O desenvolvimento da África do Sul não pode ser dissociado do continente africano", afirmou o presidente em busca de manter Pretoria atuante na renovação do continente através da valorização da UA e da NEPAD. Duas áreas temáticas foram dadas como preferência, o continente e o fortalecimento da integração político-econômica da SADC. A Agenda Africana permanece como centro da política externa com parcerias multilaterais interafricanas, através de parcerias internacionais multilaterais ou bilaterais no pilar fundamental da Cooperação Sul-Sul. Isso significa o engajamento solidário com grupos regionais ou sub-regionais do Sul, sobretudo no seu engajamento e laços políticos que o fez entrar no fórum dos BRICS, principal cúpula de líderes regionais do hemisfério Sul (OTAVIO, 2013).

\section{SADC como espaço estratégico de política externa da África do Sul}

A região da África Austral, assim como diversas divisões geopolíticas, é uma construção social baseada em interesse compartilhado e de entendimento intersubjetivo, relacionado aos antepassados de primeiros habitantes Khoisan e a um passado colonial recente na história dos países, o que influenciou os aspectos culturais, linguísticos, e em termos legais, políticos e econômicos. Outro aspecto compartilhado são os movimentos de libertação nacional com o fim de adquirir a independência em ao menos cinco países - Angola, Moçambique, Zimbábue, Namíbia e África do Sul - que estabeleceu um compromisso com o socialismo no contexto da Guerra Fria, desestabilizando o regime do apartheid apoiado pelo polo capitalista. Além do mais, os controles estabelecidos pelos brancos no Zimbábue (até 1980), Namíbia (até 1990) e África do Sul (até 1994) foram utilizados para amarrar uma estrutura para provimento

\footnotetext{
${ }^{3}$ Soft power é um termo cunhado nos anos 80 por Nye que significa a habilidade de o país conseguir o que quer através de influência e atração em vez de coerção ou pagamento, o que inclui cultura, valores e política externa. Além disso, a definição foi estendida para a habilidade de afetar outros por meio de cooptação, de persuasão, de provocação a fim de obter melhores resultados (NYE, 2011).
} 
de recursos e uma infraestrutura voltada à exportação. Isso levou a diversos países obterem uma severa desigualdade de riqueza, cuja capacidade produtiva permaneceu nas mãos da minoria não local (BAUER e TAYLOR, 2005).

Nenhum dos países foram vítimas de um golpe militar, o que demonstra o respeito e a expectativa de que civis estejam encarregados de comandar o país no seu aparato político. Entretanto, diversos conflitos e instabilidade são correntes na dificuldade de estabelecer a plena democracia em diversos Estados. Cada um deles possui um estágio, conforme os interesses econômicos e políticos constituídos em seu sistema. Ademais, a desigualdade existente no processo de modernização é demonstrada pelo PIB dos países, onde a África do Sul é, largamente, o Estado com maiores capacidades econômicas da região - 51\% do PIB da região em 2014 - conforme FMI WORLD Economic Outlook. Essas disparidades e objetivos são o que procuram as instituições criadas para a consolidação desses aspectos históricos e socioculturais comuns, e a cooperação que nasce como forma de orquestrar essas relações nos anos 90 com o fim dos regimes do apartheid é a SADC.

A Comunidade para o Desenvolvimento da África Austral (SADC, na sigla em inglês) é um bloco econômico criado em 1994 com o ingresso da África do Sul, através do qual os Estados que o compõe discutem soluções para resolução de conflitos, além de promover a cooperação política e econômica. Segundo o site oficial ${ }^{4}$, seu principal objetivo é alcançar o desenvolvimento econômico, paz, segurança e crescimento, aliviar a pobreza, melhorar o padrão e qualidade de vida da população da África Austral e financiar a integração regional para diminuir a desvantagem social, através de princípios democráticos e igualitários e de desenvolvimento sustentável (SADC, 2012). Esse fórum de cooperação regional, portanto, age de maneira mais ampla que uma zona de livrecomércio, incluindo a discussão de resoluções comuns nas áreas de desenvolvimento político, econômico, em transporte, infraestrutura, imigração e saúde. Atualmente, a SADC é composta por quinze países membros: Angola, Botsuana, República Democrática do Congo, Lesoto, Madagascar, Malaui, Maurício, Moçambique, Namíbia, Seicheles, África do Sul, Suazilândia, Tanzânia, Zâmbia e Zimbábue (SCHUTZ, 2013). finanças e investimentos; Angola, energia; Botswana, produção animal e

\footnotetext{
${ }^{4}$ Site oficial SADC: http://www.sadc.int/ 
agrária; Lesoto, conservação da água, do solo e turismo; Malauí, florestas e fauna; Maurício (sem função específica); Moçambique, transportes, cultura e comunicações; Namíbia, pesca; Suazilândia, recursos humanos; Zâmbia, minas; Zimbábue, segurança alimentar. A Tanzânia, a República Democrática do Congo e as ilhas Seicheles que aderiram mais recentemente ainda não possuem uma função (REIS DA SILVA, 2005).

A SADC é o principal palco de diálogo com a África Austral pela abrangência de temas, de número de países, possui uma população de aproximadamente 230 milhões de pessoais e um PIB de US\$ 700 bilhões (VIZENTINI, 2010). Desta forma, o bloco tornou-se um importante instrumento multilateral da África do Sul com os vizinhos para legitimar a sua liderança através de parceria, cujas decisões são avaliadas pelo grupo, seguindo os objetivos acordados. Ao mesmo tempo, valores comuns como o pan-africanismo e os direitos humanos democráticos para resolução de conflitos pacificamente são postos em evidência. Além disso, possui o objetivo de aumentar a competitividade da respectiva região e fomentar o comércio, assegurando a defesa e segurança do território, metas que promovem sustentação ao bloco.

A percepção dos Estados que fazem parte da SADC quanto à liderança da África do Sul aos poucos se modifica de uma percepção de vulnerabilidade perante o seu poderio econômico, militar e capital político, para a geração de utilidade e necessidade no consentimento das ações do grupo com o fim de auxiliá-los no desenvolvimento com responsabilidade ao bem-estar da sociedade (PRYS, 2010). Segundo Mattli (1999), um hegemon regional benevolente, como a África do Sul, vem a ser necessário para financiar o bem coletivo da integração, promovendo a liderança as negociações e construção das instituições que a compõe, a fim de compensar os Estados membros menores por perdas relativas (KRAPOHL et al, 2013). Além do mais, como o Presidente Zuma afirmou no discurso do $10^{\circ}$ aniversário da África do Sul como mantenedora da paz no continente 5 , de que a "África do Sul não consegue sobreviver de forma isolada, já que o seu desenvolvimento econômico e segurança está vinculado a estabilidade do continente" (ZONDI, 2012).

Desde Mbeki, a África do Sul vem buscando cultivar a posição de líder natural do continente africano, apesar de tentar não jogar o peso relativo econômico e militar ao

\footnotetext{
${ }^{5}$ O Relatório anual do Departamento de Relações Exteriores mostra que as tropas da África do Sul aumentaram a sua participação nas missões de paz da ONU de 123 em 1999 para 4860 em 2008. Os países que mais se beneficiaram foram Burundi, RDC, Eritreia-Etiópia, Libéria e Sudão. A África do Sul é a $17^{\mathrm{a}}$ maior contribuidor de esforços de mantimentos da paz pela ONU (LE PERE, 2013).

Conjuntura Global, vol. 4 n.3, set./dez., 2015, p. 478-494. 
redor. 0 governo sul-africano é membro ativo do NEPAD e gasta um enorme capital financeiro e diplomático, em esforços para acabar com conflitos em diversos países da África. Assim, o país vem utilizando uma tendência multilateral para criar soluções comuns às preocupações regionais, solidificando sua posição de país do Sul. Um dos exemplos é o South African Development's Community Protocol on Politics, Defense and Security Cooperation identificado como, segundo Hammerstad (p. 7, apud SOKO),

[...] uma agenda de segurança que transpõe ameaças políticos-militares bem como ameaças não-militares, incluindo-se: guerras interestatais, guerras internas, abusos em larga escala dos direitos humanos, crimes de guerra, crimes contra a humanidade, genocídio, segurança alimentar, deslocamento em massa de refugiados, imigrantes legais, desastres humanitários e naturais, doenças (particularmente o HIV-AIDS malária que possui um alto índice de infectados na região), pobreza e subdesenvolvimento, e degradação ecológica.

Desde 2002, o órgão possui um pacto de defesa mútua ainda em negociação entre todos os Estados membros que aparentemente pode comprometer a soberania, o que ainda demonstra desconfiança de ações político-militares sul-africanas (MBEBE, 2010). Esse novo paradigma de segurança proposto pela África do Sul está sendo desafiado por alguns Estados dentro da região, os quais se recusaram a aceitar a África do Sul como defensora de seus interesses (SOKO, 2003). Mesmo assim, Zuma atua na chamada quiet diplomacy, ou seja, através da promoção de diálogos entre beligerantes, conjuntamente a elementos de compartilhamento de poder, mecanismos de transição de justiça e diálogo nacional em temas econômicos em diversos conflitos.

A relevância de estabilidade dos conflitos na região está relacionada com a brutalidade, intimidação, depravação, pobreza e morte sofrida pelas suas populações que transbordam as fronteiras nacionais. Além do mais, recentes estatísticas revelam que no fim de 2009, ao redor de 456 mil, 141 mil e 22,5 mil pessoas foram registradas como refugiadas vindas da RDC, Angola e Zimbábue, respectivamente. Destes, após o Reino Unido, a África do Sul, Botsuana e Moçambique tem sido os seus principais destinos com 222 mil imigrantes no ano de 2009 somente na África do Sul, segundo dados da Agência de Refugiados da ONU (UNHCR, 2009). Apesar do foco atualmente ser a imigração na União Europeia, devido aos recentes conflitos no Magreb e na Síria, a África do Sul era, até 2010, um dos principais destinos imigratórios mundiais, sobretudo 
vindos do Zimbábue, Moçambique, Lesoto, Suazilândia, Botsuana e Malauí, todos pertencentes a SADC.

Essa realidade suscitou reações xenofóbicas contra os estrangeiros residentes, mesmo que a o governo democrático pós-apartheid tenha acabado com a diferença de cor, mas modificada para a maneira de lidar com os migrantes com e sem formação superior/técnica. A maioria dos sul-africanos tem a percepção da imigração como uma fonte de desemprego, crime, HIV-AIDS e uma ameaça à cultura nacional. Essa reação reafirma o distanciamento da população em relação às expectativas da retórica panafricanista tornando-se difíceis acordos de livre acesso de pessoas entre os países membros da SADC (KRAXBERGER e McCLAUGHRY, 2013).

Apesar das dificuldades quanto a questão de imigração, o comércio vem sendo desenvolvido de forma contundente. De forma bilateral, Zuma construiu diversas parcerias estratégicas. Angola, por exemplo, foi o país escolhido para a primeira visita de Estado do Presidente ao exterior em 2009 juntamente com 11 Ministros, o que demonstrava a solidariedade com o país, em esforço para reconstruir um espaço bilateral comercial e de cooperação militar. Esse trabalho conjunto se estabeleceu principalmente através das parcerias entre as petrolíferas angolana Sonangol e sulafricana Petro S.A., discussão sobre projetos futuros conjuntos na SADC e intensificação das redes políticas entre o MPLA e o CNA (AFRICA RESEARCH BULLETIN, 2009).

A implantação de políticas bilaterais com os países africanos em projetos geoestratégicos demonstra que além de uma Agenda Africana de paz-estabilidade e democracia/good governance, Zuma também estipula uma Diplomacia Econômica na região. Angola foi um dos exemplos da administração em dinamizar as relações econômicas (OTAVIO, 2013). A criação ou a manutenção de outros acordos comerciais nos chamados Business Foruns também são estabelecidos com outros países africanos relevantes, como, por exemplo, com Nigéria, Senegal, Tanzânia, Namíbia e Zâmbia, todos atrelados com a Diplomacia Econômica de Zuma. Conforme Hughes (2011) indica que:

A Diplomacia Econômica é vista como a elaboração de política e estratégias departamentais que facilitam a realização dos objetivos estratégicos do país na África e no mundo. Estes incluem, por exemplo, a promoção de estratégias de integração regional; o profundo engajamento de projetos como o NEPAD; o avanço nas negociações comerciais, tais como nos Acordos de Parceria Econômica e da Organização Mundial do Comércio (Rodada de Doha); na gestão 
do Southern African Customs Union (SACU) e no êxito em sua reforma e não união voltada à criação de um acordo delivre comércio africano.

Em relação ao comércio bilateral sul-africano com cada um de seus vizinhos existe uma evolução em uma disparidade de dependência. Segundo dados da UNCTAD, com um comércio que gerou US $\$ 19,1$ bilhões em 2012, a África conta com 15,1\% do total exportado pela África do Sul, sendo a região da África Austral a principal atração, ao redor de 70\% (13,4 bilhões) em 2012. A importância relativa dos vizinhos como destino das exportações da África do Sul é limitada, oscilando em torno de 10\% do total. Além disso, apenas três países do entorno do total mundial superaram $2 \%$ de participação nas exportações sul-africanas: Moçambique, Zâmbia e Zimbábue. Apesar de pequeno, esse fluxo concentra-se principalmente em manufaturas intensivas em recursos, de baixa e de média tecnologia, o que não ocorre para o resto do mundo (IPEA, 2014). Com relação às importações, embora tenha triplicado em 2010 a participação no fluxo comercial da África do Sul desde 2000, ainda não alcançaram o patamar de 5\% do total e se concentram principalmente em produtos primários e manufaturas intensivas em recursos.

Para desenvolver melhores relações na SADC, a proposta da política externa sulafricana é a de se apoiar no Regional Indicative Strategic Development Plan (RISDP) para acelerar a integração regional, trabalhando em três direções: Área de Livre Comércio, aumentando os investimentos em infraestrutura; União Aduaneira, com o fim de aumentar o comércio consideravelmente e um vínculo político através de um maior alinhamento com as estratégias e programas nacionais (HURREL, 2009). Seus objetivos foram estabelecidos na intensificação em defesa, em infraestrutura, no transporte, na coordenação de planos multisetoriais e na harmonização de políticas industriais, além da criação de um fundo próprio para desenvolvimento, com previsão de aumento de manufatura na percentagem do PIB para 25\% até 2015 (LANDSBERG e KONDLO, 2007). Além disso, o RISDP inclui uma rede de infra-estruturais regionais integradas rentáveis e eficientes, que inclui os setores de energia, água, telecomunicação, turismo e transporte.

Como um conjunto de fatores que faz a África Austral ter uma realidade distinta ao afro-pessimismo gerado nos anos 90 ao continente é a sua infraestrutura herdada do passado colonial britânico e português. Enclaves mineradores como a África do Sul, Namíbia, Zâmbia, Angola e a atual RDC exigiram a construção de um sistema de ferrovias 
e portos, bem como interconexões sub-regionais e mediterrâneas que desenvolveram centros urbanos, e, por consequência construções de hidroelétricas para a geração de energia interna. Entretanto, esses investimentos tinham caráter exploratório e colonizador e não desenvolviam a região no aspecto de conectar-se. Por isso, atualmente, desde o fim do regime do Apartheid, a África do Sul faz esforços para desenvolver infraestrutura conjunta como o corredor de Desenvolvimento de Maputo e a Rodovia Trans-Kalahari que liga o porto de Maputo no Índico a Baia Walvis na Namíbia no Atlântico, passando por importante polo econômico da África do Sul e Botsuana, além de outros diversos investimentos em infraestrutura na região (SIMON, 2014).

Todos esses investimentos projetam um aumento na estabilidade política, econômica, de mercado de livre circulação de bens e serviços inter-regional, com melhora na infraestrutura, permitindo a competitividade para um fluxo de investimento externo direto do exterior, até agora de pouca relevância internacional. Os Investimentos Externos Diretos aumentaram em US\$ 50 bilhões em 2012, um aumento de $5 \%$ comparado ao ano anterior e de 12,3\% desde 2003. Mesmo assim, a proporção mundial do continente ainda é pequena - 3,7\%, com o fluxo na África Austral passado de US\$1.3 bilhão em 2003 para US\$5.4 bilhões em 2012 - uma composição de crescimento de 18,6\% em uma década (UNCTAD e Banco Mundial, 2003-2012), com grande presença das empresas sul-africanas nas áreas de alimentos, bebidas, telecomunicações, serviços financeiros, farmacêuticos e varejo (ECIC, 2012).

Essa estratégia que também vincula a integração comercial de Jacob Zuma na região da SADC de crescimento nas ações de coesão demonstra o engajamento em todos os âmbitos ao afro-centrismo em sua política externa. Mesmo com dificuldades sociais, logísticas, de subdesenvolvimento e de instabilidades políticas, o universalismo sulafricano que vem sendo desenvolvido no país desde Mandela gera ações multilaterais e de líder emergente regional, abrangendo a sua cooperação Sul-Sul, africana, integracionista na SADC e atrativa de fluxos de investimentos de países desenvolvidos. Nesse sentido, Zuma se utiliza para estabelecer a sua política da vertente filosófica africana 'Ubuntu' - noção existente na língua zulu e xhosa, ligado ao aspecto de harmonia do universo como um todo orgânico - que cria uma humanidade comum e providencia uma visão de mundo inclusiva e construtiva na modelação do seu envolvimento na ordem global (BOHLER-MULLER, 2012). 


\section{Considerações Finais}

Estabelecer-se como um líder regional tem diversas dificuldades e consequências, já que os interesses nacionais normalmente são os que prevalecem. Ser percebido como um país que visa manter a coesão de um grupo de Estados por meio multilateral sem a atribuição de um caráter ambicioso é de difícil consideração pelos outros países. A liderança é normalmente confundida com ações hegemônicas, pois o poderio militar, econômico, ideológico ou político influencia a tomada de decisões, o que se torna um espaço competitivo. Além do mais, a cooperação é relevância sine qua non para que a liderança possa ser exercida, portanto, não basta aceitar o poder exercido pelo líder, deve-se compartilhar o custo-benefício para gerar as transformações requeridas aos problemas da região.

Demonstrativamente, o poder militar, econômico, comercial, político, institucional sul-africano é mais forte do que os seus vizinhos, mesmo assim, a interdependência dos países é cada vez maior. Os blocos econômicos se constituem como meio multinacional para diálogo e para dar maior força externamente aos seus valores e normas acurados conjuntamente. 0 isolacionismo regional não existe mais à África do Sul e o seu relacionamento tende cada vez mais aumentar, tentando construir um espaço de cooperação e de coesão.

A SADC possui 15 países, cada qual com suas diferentes características e dificuldades, apesar de que muitos problemas socioeconômicos e conflitos são passados de forma transnacional e por isso devem ter um apoio Estatal para tentar coibir essas ações. Além do mais, a competitividade da região para o seu desenvolvimento deve possuir auxílio de um Estado desenvolvimentista que capacite um complexo industrial, uma infraestrutura, emprego, capacitação, bem-estar da população sem a imposição externa. É dessa maneira com que Zuma estabelece maiores parcerias estratégicas e consolida a sua Agenda Africana e Diplomacia Econômica.

Mesmo assim, ainda existem diversos desafios e limitações a serem superadas pela região da África Austral para a consolidação dessa integração chegar ao desenvolvimento com autonomia e a África do Sul realmente se tornar o seu líder. A única forma de isso acontecer é através do engajamento do país na estrutura da SADC, agindo de forma sempre multilateral e quando é requerida, especialmente nos quesitos Conjuntura Global, vol. 4 n.3, set./dez., 2015, p. 478-494. 
de governança e segurança. Além disso, o país deve parar de competir entre os outros países africanos a um assento permanente no Conselho de Segurança e agir conjuntamente para a África ter uma representação. Com o auxílio sul-africano financeiro e de capacitação militar, a SADC terá a oportunidade e habilidade para operar de forma a manter a paz em áreas de crises com a atuação de sua brigada de emergência.

A fim de criar uma coesão de valores intrarregionais os Estados devem engajar-se na rede de contatos entre a sociedade, empresas, universidades, através de rodovias e ferrovias de ligação ou abrindo espaço migratório de livre circulação de pessoas, caso haja conexão no desenvolvimento da região. A intenção sul-africana de crescimento de exportações de seus bens manufaturados podem ser um dos motivos de interesse para que grupos da elite também possam gerar o compromisso de alavancar um espaço de afro-otimismo. Essas pretensões serão as formas para desenvolver um espaço de progresso na África Austral com liderança sul-africana, apesar das limitações que serão sempre encontradas e desafios a serem superados.

\section{REFERÊNCIAS}

AFRICAN ECONOMIC OUTLOOK. Statistic. Disponível em: $<$ http://www.africaneconomicoutlook.org/en/statistics/>. Acesso em: 11 de setembro de 2015.

AFRICA RESEARCH BULLETIN. Angola-South Africa Strategic Partnership. Ago-Set 2009.

BAUER, Gretchen; TAYLOR, Scott D. Politics in Southern Africa: State \& Society in Transition. Boulder: Lynne Rienner Publishers, 2005.

BOHLER-MULLER, Narnia. Nuanced Balancing Act: South Africa's National and International Interests and its 'African Agenda'. Johannesburg: South African Institute of International Affairs, Set 2012.

HABIB, Adam. South Africa's Foreign Policy: Hegemonic Aspirations, Neoliberal Orientations and Global Transformation. South African Journal of International Affairs, London, v.2, n.16, p.143-159, 2009. Disponível em:<http://www.gigahamburg.de/dl/download.php?d=/english/content/rpn/conferences/habib.pdf>.

Acessoem: 04 out 2014.

HAMILL, James; LEE, Donaa. A Middle Power Paradox? South African Diplomacy in the Post-apatheid Era. International Relations, London, v.15, n.4, p.33-59, 
2001.Disponívelem:<http://ire.sagepub.com/content/15/4/33.full.pdf>. Acesso em: 27 set 2014.

HERZ, Mônica. Análise Cognitiva e Política Externa. Contexto Internacional, Rio de Janeiro, vol. 18, no 1, jan-jun 94, pp. 75-89.

HURREL, Andrew et. al. Os BRICs e a Ordem Global, Rio de Janeiro, Editora FGV, 2009.

KONDLO, Kwandi; LANDSBERG, Chris. South Africa and the "African Agenda". Policy: issues and actors. Johannesburg, v.20, n.13, p.1-14, 2007.Disponívelem: $<$ www.cps.org.za/cps\%20pdf/pia20 13.pdf >.Acessoem 06 out 2014.

KRAPOHL, Sebastian; MEISSNER, Katharina L e MUNTSCHICK, Johannes. Regional Powers as Leaders or Rambos of Regional Integration? Unilateral Actions of Brazil and South Africa and their Negative Effects on MERCOSUR and SADC. Universidade de Bamberg, Instituto de Florença e Universidade de Mainz, 2013.

KRAXBERger, Brennan M. e McClaughry, Paul A. South Africa in Africa: a geopolitical perspective. Canadian Journal of African Studies.Ago 2014.Acessoem: $<$ http://www.trandfonline.com/loi/rcas20 $>$. Acesso em: 20 de fev 2015.

LANDSBERG, Chris. A Política Externa do Governo Jacob Zuma: Associação ou dissociação? Austral: Revista Brasileira de Estratégia e Relações Internacionais, Porto Alegre, v.1, n.1, p.75-102, 2012c. Disponível em: <http://seer.ufrgs.br/austral/article/view/27993/18015>. Acesso em 02 out 2014.

LE PERE, Garth. Critical Themes in South Africa's Foreign Policy: an overview. Gabriel \& Associates e Department of Political Sciences, Universidade de Pretoria, África do Sul.

MBEBE, Fernando Rodrigo. A arquitetura de segurança na África Austral (SADC): surgimento e desenvolvimento de uma comunidade de segurança. Dissertação de Mestrado, Porto Alegre, 2010.

NYE, Joseph Jr. The Future of Power. Public Affairs, New York, 2011.

OLIVEIRA, Amâncio Jorge de; ONUKI, Janaina. Coalizões Sul-Sul e Multilateralismo: Índia, Brasil e África do Sul. Contexto Internacional, São Paulo, vol. 28, no 2, pp. 465504, julho/dez 2006.

OTAVIO, Anselmo. A África do Sul Pós-Apartheid: a inserção continental como prioridade na nova geopolítica mundial. Dissertação mestrado, UFRGS, FCE, Estudos Estratégicos Internacionais, Porto Alegre, 2013.

PEREIRA, Analúcia Danilevicz e VISENTINI, Paulo G. Fagundes. África do Sul: História, Estado e Sociedade. Brasília. FUNAG/CESUL, 2010.

PRYS, Miriam. Analytical essays: Evaluation, Synthesis, Reflection. Hegemony, Domination, Detachment: Differences in Regional Powerhood. International Studies Review, v. 12, pp. 479-504, 2010.

REIS DA SILVA, André Luiz. África contemporânea: os novos desafios da segurança, desenvolvimento e autonomia (1960-2005). Monografia, Porto Alegre, n. 1, 2005. 
SCHUTZ, Nathaly Xavier. O Pan-africanismo e o Processo de Integração na África Austral: uma perspectiva histórica. Conjuntura Internacional, Belo Horizonte, v.10, n.3, p.50-58, 2을 2013.

SIMON, David. The changing contexto for regional integration in Southern Africa: how adaptive are its regional institutions? South Afican Geographical Journal, Nov 2010. Disponível em:<http://www.trandfonline.com/loi/rsag20 $>$. Acesso em 10 Mar 2015.

SOKO, Mills. A África do Sul e as ameaças tradicionais e não-tradicionais à segurança regional. In: A África do Sul e o IBAS: desafios da segurança humana. Orgs: KORNEGAY, Francis e DADA, Jabulani. Porto Alegre: Editora UFRGS/FUNAG/MRE, 2007.

TSCHEOLA, Johannes. South Africa's form of globalization: a continental posture paradox for insertion and dependence. Political Geography, v 21, pp 789-811, 2002.

UNHCR - United Nations High Commissioner for Refugees. 2009 Global Trends Refugees, Asylum-seekers, Returnees, Internally Displaced and Stateless Persons. Division of Programme Support and Management, Jun 2010. Disponível em: <http://www.unhcr.org/4c11f0be9.html>. Acesso em: 17 de julho de 2015.

VIZENTINI, Paulo Fagundes e PEREIRA, Analucia. África do Sul: História, Estado e Sociedade. Brasília: FUNAG/CESUL, 2010.

VIZENTINI, Paulo Fagundes. A África na Política Internacional: o sistema interafricano e sua inserção mundial. 1ํㅡ ed. Curitiba: Juruá, 2012.

YANACOPOLUS, Helen. The incongruent faces of a middle power: South Africa's emergence in international development. Paper Prepared for the IBSA Convention Edinburgh, Scotland, 20-22 June, 2012.

ZONDI, Siphamandla. South Africa in Southern Africa: a Perspective. Friedrich-EbertStiftung, Maputo, 2012. 